\title{
Correction to: Fasciocutaneous Type Axial Pattern Local and Regional Flaps: Alternative to Free Flaps?
}

\author{
Bipin T. Varghese ${ }^{1}$
}

Published online: 6 September 2021

(c) Indian Association of Surgical Oncology 2021

\section{Correction to: Indian Journal of Surgical Oncology https://doi.org/10.1007/s13193-021-01405-6}

The original version of this article contained a mistake.

The added reference in the final version was placed in the 13th position instead of its intended position of 6th as communicated by the author during the proof reading.

This is being corrected in this publication.

Publisher's Note Springer Nature remains neutral with regard to jurisdictional claims in published maps and institutional affiliations.

The original article can be found online at https://doi.org/10.1007/ s13193-021-01405-6.

Bipin T. Varghese

bipintv@gmail.com

1 Head and Neck Surgery, Department of Surgical Services, Regional Cancer Centre, Thiruvananthapuram 695011, India 